\title{
Polycystic Ovary Syndrome (PCOS) and Fertility
}

\author{
Guilherme Barbosa1, Larissa Bianca Paiva Cunha de Sá1, \\ Denise Rosso Tenório Wanderley Rocha1, Alberto Krayyem Arbex ${ }^{1,2}$ \\ ${ }^{1}$ Division of Endocrinology, IPEMED Medical School, São Paulo, Brazil \\ ${ }^{2}$ Harvard T. H. Chan School of Public Health, Harvard University, Boston, USA \\ Email: meduna_gui@yahoo.com.br
}

Received 25 November 2015; accepted 18 January 2016; published 21 January 2016

Copyright (C 2016 by authors and Scientific Research Publishing Inc.

This work is licensed under the Creative Commons Attribution-NonCommercial International License (CC BY-NC).

http://creativecommons.org/licenses/by-nc/4.0/

(c) $)$ () \& 8 Open Access

\section{Abstract}

The polycystic ovary syndrome (PCOS) is defined as a combination of hyperandrogenism (hirsutism and acne) and anovulation (oligomenorrhea, infertility, and dysfunctional uterine bleeding), with or without the presence of polycystic ovaries on ultrasound. It represents the main endocrine disorder in the reproductive age, affecting $6 \%-15 \%$ of women in menacme. It is the most common cause of infertility due to anovulation, and the main source of female infertility. When in the presence of a menstrual disorder, the diagnosis of PCOS is reached in $30 \%-40 \%$ of patients with primary or secondary amenorrhoea and in $80 \%$ of patients with oligomenorrhea. PCOS should be diagnosed and treated early in adolescence due to reproductive, metabolic and oncological complications which may be associated with it. Treatment options include drugs, diet and lifestyle improvement.

\section{Keywords}

Polycystic Ovary Syndrome, Infertility, Anovulation, Hyperandrogenism, Insulin Resistance

\section{Introduction}

The polycystic ovary syndrome PCOS is conventionally defined as a combination of hyperandrogenism (hirsutism and acne) and anovulation (oligomenorrhea, infertility, and dysfunctional uterine bleeding) with polycystic ovaries. At ultrasound [1], it is the main gynecological endocrinopathy of reproductive age, affecting $6 \%-10 \%$ of women in menacme. It is the most common cause of infertility due to anovulation. In many countries, it represents the leading cause of female infertility [2]. The specific pathophysiology of this syndrome has not yet 
been established, however it is associated with the presence of insulin resistance, obesity, diabetes mellitus type 2, dyslipidemia, metabolic syndrome, hypertension, cardiovascular disease, hyperplasia and endometrial carcinoma [3]. When it is considered in the presence of menstrual disorder, diagnosis of PCOS is obtained in $30 \%$ $40 \%$ of patients with primary or secondary amenorrhoea and in $80 \%$ of patients with oligomenorrhea [4] [5].

\section{Classification}

PCOS affects women of childbearing age without higher prevalence by ethnic groups, but the signs and symptoms may differ by ethnicity. Today, the most widely used tool for diagnosing PCOS are still the "Rotterdam Criteria"; its prevalence is up to five times higher than when defined by the NIH criteria [6].

Only a third of patients have the classic form of the syndrome described by Stein and Leventhalin 1935 [3]. The concept of PCOS is very broad; it is clinically characterized by the presence of menstrual dysfunction, chronic anovulation and hyperandrogenism [7]. The three main consensuses on PCOS defined the criteria for diagnosis which are highlighted below:

\subsection{The Rotterdam ESHRE/ASRM-Sponsored PCOS Consensus Workshop Group Fertility and Sterility (2003)}

Presence of 2 out of 3 criteria:

1) Oligoovulation or anovulation;

2) Clinical or biochemical signs of hyperandrogenism;

3) Polycystic ovaries on ultrasound.

As defined by the Rotterdam Criteria in 2003, polycystic ovaries have as their concept, the presence of at least one ovary of 12 or more follicles with diameters of $2-9 \mathrm{~mm}$ and/or increase the ovarian size $>10 \mathrm{ml}$ (The ESHRE Rotterdam/ASRM, 2004).

In addition to these criteria, other medical conditions that can cause chronic anovulation and androgen excess should be excluded, such as:

- Hyperprolactinemia/hyperthyroidism;

- Congenital adrenal hyperplasia, classical and nonclassical form;

- Cushing's syndrome; secretory ovarian tumor of adrenal androgens [6].

\subsection{The Thessaloniki ESHRE/ASRM-Sponsored PCOS (2006)}

In 2006, The Androgen Excess and PCOS Society (AE-PCOS) published its positioning regarding the diagnosis of polycystic ovary syndrome. According to this association, the androgen excess needs to be present, either by clinical signs, or by biochemical hyperandrogenism. Thus, for diagnosing of the syndrome, two of the following criteria would be necessary:

1) Oligo and/or anovulation and polycystic ovaries on ultrasound;

2) Clinical or laboratory evidence of androgen excess [6] [8].

To get to these criteria, they considered the syndrome as an androgen excess disorder and its fundamental characteristics: menstrual or ovulatory dysfunction, hyperandrogenemia, clinical hyperandrogenism and polycystic ovarie. Further, the association pointed out that, the resulting phenotypes from the combination of such characteristics, as a group, but not necessarily individually, have insulin resistance and attendant risk of metabolic abnormalities [6] [8].

\subsection{The Amsterdam ESHRE/ASRM—Sponsored 3rd PCOS Consensus, 2012}

Most recently defined presence of 2 out of 3 criteria:

- Menstrual disfunction and/or polycystic ovary;

- Hyperandrogenia and/or hyperandrogenism;

- The ultrasound showing a polycystic ovary [9].

\section{Epidemiology}

There are few epidemiological studies about the PCOS, mainly on population-based. The vast majority of published studies consist in data from clinical trials, many of them carried out in populations in endocrine care services or infer- 
tility clinics, with sample and classification problems, leading to difficulties in generalizability and comparability.

The United States and Europe are leading research into PCOS and more recently, some data were published by authors from outside this axis. The difficulties in classification PCOS and the diagnostic criteria to identify the main phenotypes have been discussed only in the last two decades, having difficulty finding a consensus [10]. It is estimated that worldwide, 105 million women between 15 and 49 years of age show PCOS, the same being responsible for $72 \%$ to $82 \%$ of causes of hyperandrogenism [3].

\subsection{National Data}

It is estimated that worldwide, there are nearly 100 million women with this disease. In Brazil, if we consider the last IBGE census data [11] might be 2.5 million women with this syndrome, about 800,000 women in the state of São Paulo, 300,000 in the state of Rio de Janeiro, 180,000 in the state Parana and 400,000 in the state of Minas Gerais [12]. In Brazil, there is a shortage of epidemiological data on PCOS. Among the few national studies published on the subject and indexed in major databases, are all clinical investigations, except for an anthropological study. A single prevalence study conducted until this moment in the country was made in Salvador, with randomized sample of attended women in primary health care. Using diagnostic criteria of the Consensus of Rotterdam, a prevalence of $8.5 \%$ (95\% CI: 6.8 to 10.6) was estimated as the first initiative in the epidemiological investigation of PCOS in Brazil and in South America [12].

\subsection{Pathogenesis}

The etiology of PCOS is not yet completely known. It is believed that it is a complex multigenic disorder, including abnormalities in the hypothalamic-pituitary axis, steroidogenesis and insulin resistance [13].

\subsection{Abnormal Steroidogenesis}

Most of authors consider that abnormal steroidogenesis of ovarian or adrenal origin is the primary disorder PCOS. High concentrations of circulating testosterone and dehydroepiandrosterone (DHEA) occur in 60\% to $80 \%$ and $20 \%$ to $25 \%$ of women with PCOS, respectively [14] [15].

\subsection{Insulin Resistance}

In the last decade, it has been observed that the majority of women with PCOS presents some degree of insulin resistance, even non obese. Studies suggest the existence of Genetic predisposition, which ends up manifesting as a result of life style and obesity [16]. The resulting hyperinsulinemia insulin resistance causes an increase in both the production of androgens as in the biologically active portion. The joint mechanism proposed for this could be a relation with the changes in swimming-insulin receptors and the enzyme that regulates adrenal and ovarian androgen production [17].

\subsection{Abnormalities in Pituitary Function}

The clutter in the release of gonadotropins: luteinizing hormone (LH) and follicle-stimulating hormone (FSH) from the pituitary have been implicated in the pathogenesis of PCOS. In almost patients with PCOS, the relation of LH/FSH is altered, being higher the LH secretion in relation to FSH, resulting in an increased production of androgens by theca cells, and anovulatory cycles [18] [19]. However, more recent studies have shown that these changes in LH levels are a secondary event and non-primary [19]. The excess androgen changes the regulation of female hormones, resulting in increased estrogen levels, menstrual irregularity and infertility [13] [15].

\subsection{Genetic Factors}

The type of genetic inheritance is polygenic in most of the cases, and the genes most frequently associated with PCOS are related to the biosynthesis, action and regulation of androgens, genes involved in insulin resistance and chronic inflammation and atherosclerosis [20].

Presently, the various clinical manifestations of this disease are responsible for making these women are considered an integral part of different phenotypes with the presence of hyperandrogenism, menstrual irregularity and changes of the ovaries on ultrasound [21]. Familial occurrence is common, especially when there are first degree relatives $(20 \%-60 \%)$ [22]. 


\subsection{Family Gene Mutation}

Ehrmann (2005) suggests that PCOS is a complex disorder. Genomic variants in genes associated to the biosynthesis, to the regulation and action of androgens (CYP17, CP21, CP11 $\alpha, 17 \beta$-HSD5, SHBG, receptor androgênico, 11 $\beta$-HSD and e H6PD), to the action and secretion of insulin (INSR, VNTR, IRS-1, IRS-2, CAPN10, PPAR $\gamma$, system IGF), to the secretion of gonadotropins and action (follistatin), and to the synthesis and retinoic acid metabolism, as well as pro-inflammatory genotypes (Variants of the genes of TNF-, IL-6) might be involved in genetic predisposition PCOS [20] [23] [24].

\subsection{Environmental Factors}

Environmental factors are also related in the occurrence of PCOS. The Rotterdam Consensus suggests a carrying out screening of the metabolic syndrome in all women with PCOS and obesity suffer. About $50 \%$ of women PCOS are suffering from obesity. The Consensus of Rotterdam (2004) suggests carrying out screening for metabolic syndrome in all women with PCOS and obese [6].

\section{Clinical Manifestations}

Dermatological clinical manifestations of hyperandrogenism include: hirsutism, acne, seborrhea, alopecia and, in severe cases, signs of virilization. There is considerable heterogeneity in the clinical practice, as well as can be variation in the same patient over time. Moreover, hyperandrogenism cannot define peripheral manifestations as observed mainly in Asian women [6] [25].

\subsection{Hirsutism}

Hirsutismis defined as an excessive growth of terminal hair in androgen dependent areas of women. Is one of the most widely used clinical criteria for the diagnosis of androgen excess and is observed in $50 \%-80 \%$ of patients with hyperandrogenism [6] [25].

The Ferriman-Gallwey scale is used for diagnosis of hirsutism, considered present when the score is $>8$ [26].

The hair follicles composition occurs during fetal development and its concentration reflects ethnic differences. The hair growth speed varies according to the genetic differences in the $5 \alpha$-reductase enzyme activity that converts testosterone to dihydrotestosterone (DHT), which is the most potent metabolite. It is established that hirsute women have increased the activity on 5a-reductase in the hair follicle. A follicles activity on 5a-reductase is stimulated by hyperandrogenism, by insulin growth factor, (insulin-like growth factor-1, IGF-1) and by the own insulin [27]. In hirsutism, there is increase in terminal hair in dependent androgens areas [26] (Figure 1).

\subsection{Acne}

Acne is a disorder of the pilosebaceous unit, with lesions on the face, neck, back and chest area. The importance

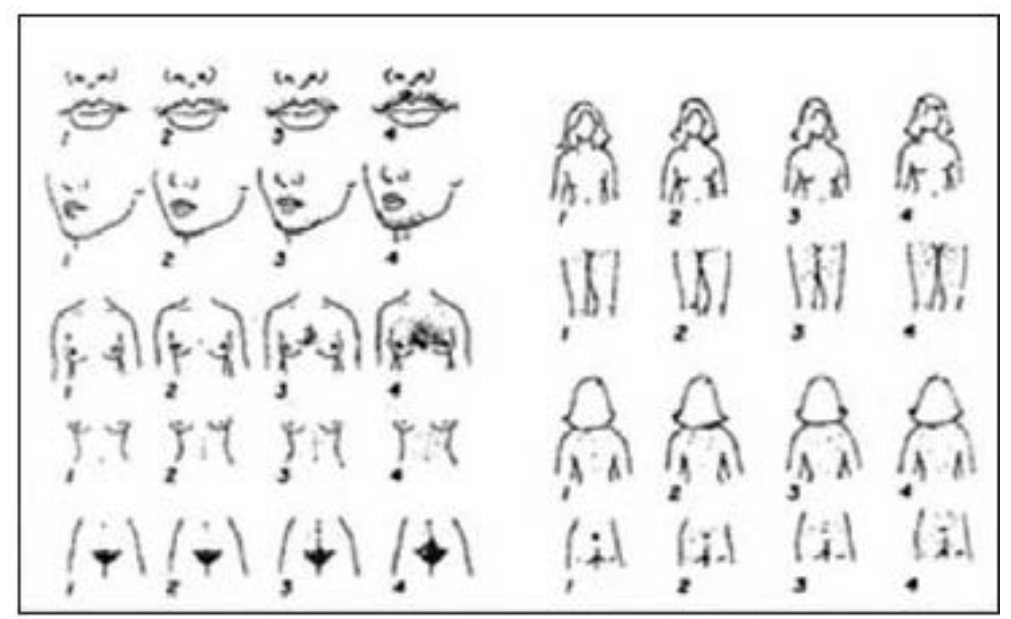

Figure 1. Modified semiquantitative guide of Ferriman and Gallwey (1961). 
of androgens in the acne pathogenesis is well-known and authenticated. As vulgaris acne, the androgen levels are usually normal. It is believed that the local conversion has been increased for a greater receptors sensibility for androgens in patients with acne in relations to normal population. Perhaps, it represents the most important cause in the disease activation [28]. Numerous studies have tried to associate the clinical presentation of acne with hyperandroge-agency markers [29]. Although some have shown a correlation between acne and high levels of dehydroepiandrosterone sulfate (DHEA-S), DHT, androstenedione, testosterone and IGF, others do not corroborate this conclusion [30].

\subsection{Androgenetic Alopecia}

The Androgenetic alopecia in women is characterized by hair loss in the central region of the scalp, with important psychosocial repercussions. In the presence of androgens with increased levels of 5-alpha-reductase, the higher concentration of androgen receptors, and lower levels of cytochrome p450 enzyme, is shortened anagen phase and terminal follicles suffer miniaturization, becoming vellus hairs [31]. Most patients with Androgenetic alopecia have the normal endocrine function. The anamnesis and physical examination are important to search of other signs of hyperandrogenism [25].

\subsection{Acantosenigricans}

The Acanthosisnigricansis characterized by the presence of a brown and velvety plate with accentuation in the furrows of skin. The dermatopatology is most commonly observed in the neck and intertriginous areas such as armpits, groin and inframammary region and it is reported in 5\% of patients PCOS [32]. Although to be associated with obesity, PCOS and diabetes, may be present in genetic diseases, drug reaction (nicotinic acid) and malignancies. The presence of acanthosisnigricans indicates the glucose tolerance test. When severe, extensive and progressive, may be associated with malignancy, especially when the mucus is also involved [32].

\section{Polycystic Ovary Syndrome PCOS and Fertility}

PCOS is characterized by anovulation due to a developmental defect of follicles beyond $10 \mathrm{~mm}$ in size. The clinical manifestations, including infertility, are related to the hypersecretion of LH (70\%) present in women with hyperandrogenism anovulatory women, (the ratio of LH/FSH ratio and high increase in ovarian androgen production). Most of the cycles are anovulatory, making it essential to induce ovulation [33]. Infertility has been considered by the World Health Organization (WHO) as a public health problem. One of the central goals of the UN Conference Programme of Action on Population and Development in 2015 was to guarantee, for all individuals, access to quality reproductive health services [34]. The agency defined infertility as the absence of pregnancy after two years of regular intercourse, without using any contraception method. However, there is a consensus that, after one year, a process of assessment of possible factors involved should begin [33]. The ESHRE/ASRM recommends that, before startig any intervention, acounseling before conception should emphasize the importance of lifestyle changes, especially weight loss and regular exercises in overweight patients, smoking cessation, and reducing alcohol consumption. Regarding ovulation inducing drugs, all are associated with the increase in multiple pregnancies, obstetric and neonatal risks [35] [36]. Among the most commonly found female's causes of infertility, it is possible to observe structural changes, ovulatory changes, immune disorders and endometriosis. Infertility patterns may be influencedby many factors, such as the woman's age, frequency in sexual activity, woman's weight and smoking, among others. This way, different techniques should be used to reach an accurate diagnosis [37]. About 50\% of infertile women have also obesity. There is a clear association between obesity and menstrual irregularities, since the adipose tissue is the largest peripheral area for the aromatization of androgens to estrogens, contributing to estrogen production [33]. Women with PCOS have a greater risk of anovulation and infertility. The progesterone dosage may be useful as an additional screening test. Itis also recommendedto exclude other infertility causes besides anovulation, in couples in which the woman has PCOS. The diagnosis of PCOS is very important, because it identifies the metabolic risks, the potential cardiovascular risk and mainly because such a diagnosis interferes directly with the fertility status of these patients [38].

\section{Discussion and Concluding Remarks}

PCOS is recognized as the most common gynecological endocrinopathy, affecting $5 \%-10 \%$ of women in 
childbearing age. It is also the most common cause of anovulatory infertility. However, there are some difficulties in its diagnosis due to different proposed diagnostic criteria [39] [40]. This is a very heterogeneous syndrome, both in terms of clinical presentation and laboratory manifestations. Women with PCOS have been presented a greater risk of endometrial cancer, which is related to the estrone increase and the high prevalence of anovulatory cycles which favor the endometrial hyperplasia, as it is already known. The overweight is also linked to this type of cancer and represents, therefore, an additional risk factor for endometrial cancer in these patients [41]. Researches also reported the obesity role in the occurrence of PCOS and its infertility relation. [42], a recent study found that obesity by itself was associated with the reduction of ovulatory rates, increasing in the abortion numbers of late pregnancy complications, and perhaps, therefore, increasing the infertility risk which was inherent to the syndrome. Anxiety, depression, stress and personal dissatisfaction, frequently reported by women who live with PCOS may be aggravated by the image body change for consequence of weight gain [43]. PCOS should be diagnosed and treated already in adolescence due to reproductive, metabolic and oncological complications that probably are associated with it. The best way of prevention is through leading an adequate diet and a healthy lifestyle.

\section{References}

[1] Franks, S. (1989) Polycystic Ovary Syndrome: A Changing Perspective. Clinical Endocrinology, 31, 87-120. http://dx.doi.org/10.1111/j.1365-2265.1989.tb00457.x

[2] Spritzer, P.M. (2002) Revisitando o hirsutismo. Arquivos Brasileiros de Endocrinologia \& Metabologia, 46,127-136.

[3] Azziz, R., Carmina, E., Dewailly, D., Diamanti-Kandarakis, E., Escobar-Morreale, H.F., Futterweit, W., Janssen, O.E., Legro, R.S., Norman, R.J., Taylor, A.E. and Witchel, S.F.; Androgen Excess Society (2006) Positions Statement: Criteria for Defining Polycystic Ovary Syndrome as a Predominantly Hyperandrogenic Syndrome: An Androgen Excess Society Guideline. The Journal of Clinical Endocrinology \& Metabolism, 91, 4237-4245.

[4] Goldzieher, J.W. and Young, R.L. (1992) Selected Aspects of Polycystic Ovarian Disease. Endocrinology and Metabolism Clinics of North America, 21, 141-171. http://dx.doi.org/10.1056/NEJM199509283331307

[5] Franks, S. (1995) Polycystic Ovary Syndrome. The New England Journal of Medicine, 333, 853-861.

[6] Rotterdam ESHRE/ASRM-Sponsored PCOS Consensus Workshop Group (2004) Revised 2003 Consensus on Diagnostic Criteria and Long Term Health Risks Related to Polycystic Ovary Syndrome PCOS (Review). Human Reproduction, 19, 41-47.

[7] Baracat, E.C. and Soares-Junior, J.M. (2007) Ovários policísticos, resistência insulínica e síndrome metabólica. Revista Brasileira de Ginecologia e Obstetrícia, 29, 117-119. http://dx.doi.org/10.1590/S0100-72032007000300001

[8] (2006) The Thessaloniki ESHRE/ASRM-Sponsored PCOS Consensus Workshop Group.

[9] (2012) Consensus on Women'S Health Aspects of Polycystic Ovary Syndrome PCOS: The Amsterdam ESHRE/ ASRM-Sponsored 3rd PCOS Consensus Workshop Group.

[10] Ning, N., Balen, A., Brezina, P.R., Leong, M., Shoham, Z., Wallach, E.E. and Zhao, Y. (2013) How to Recognize PCOS: Results of a Web-Based Survey at IVF-Worldwide.com. Reproductive Biomedicine, 26, 500-505. http://dx.doi.org/10.1016/j.rbmo.2013.01.009

[11] IBGE (2000) Diretoria de Pesquisas. Departamento de População e Indicadores Sociais. Censo Demográfico.

[12] Fernandes, L.G. (2013) Síndrome dos ovários policísticos: Uma abordagem epidemiológica. Tese ao Programa de PósPrograma de Pós-graduação graduação graduação em Saúde em Saúde Coletiva da Universidade Federal da Bahia. https://repositorio.ufba.br

[13] Yarak, S., Bagatin, E., Hassun, K.M., Talarico, S. and Parada, M.O.A. (2005) Hyperandrogenism and Skin: Polycystic Ovary Syndrome and Peripheral Insulin Resistance. Anais Brasileiros De Dermatologia, 80, 395-410.

[14] Hoyt, K.L. and Schmidt, M.C. (2004) Polycystic Ovary (Stein-Leventhal) Syndrome: Etiology, Complications, and Treatment. Clinical Laboratory Science: Journal of the American Society for Medical Technology, 17, 155-163.

[15] Buccola, J.M. and Reynolds, E.E. (2003) Polycystic Ovary Syndrome: A Review for Primary Providers. Primary Care: Clinics in Office Practice, 30, 697-710. http://dx.doi.org/10.1016/s0095-4543(03)00089-7

[16] Moura, H.H.G., Costa, D.L.M., Bagatin, E., Sodré, C.T. and Manela-Azulay, M. (2011) Síndrome do ovário policístico: Abordagem dermatológica. Anais Brasileiros de Dermatologia, 86, 111-119.

[17] Harwood, K., Vuguin, P. and DiMartino-Nardi, J. (2007) Current Approaches to the Diagnosis and Treatment of Polycystic Ovarian Syndrome in Youth. Hormone Research in Paediatrics, 68, 209-217. http://dx.doi.org/10.1159/000101538 
[18] Norman, R.J., Dewailly, D., Legro, R.S. and Hickey, T.E. (2007) Polycystic Ovary Syndrome. Lancet, 370, $685-697$. http://dx.doi.org/10.1016/S0140-6736(07)61345-2

[19] Doi, S.A. (2008) Neuroendocrine Dysfunction in PCOS: A Critique of Recent Reviews. Clinical Medicine \& Research, 6, 47-53. http://dx.doi.org/10.3121/cmr.2008.796

[20] Escobar-Morreale, H.F., Luque-Ramírez, M. and San Millán, J.L. (2005) The Molecular-Genetic Basis of Functional Hyperandrogenism and the Polycystic Ovary Syndrome. Endocrine Reviews, 26, 251-282. http://dx.doi.org/10.1210/er.2004-0004

[21] Xita, N. and Tsatsoulis, A. (2006) Review: Fetal Programming of Polycystic Ovary Syndrome by Androgen Excess: Evidence from Experimental, Clinical, and Genetic Association Studies. The Journal of Clinical Endocrinology \& Metabolism, 91, 1660-1666. http://dx.doi.org/10.1210/jc.2005-2757

[22] Legro, R.S., Barnhar, T.H.X., Schlaff, W.D., Carr, B.R., Diamond, M.P., Carson, S.A., Steinkampf, M.P., Coutifaris, C., Mcgovern, P.G., Cataldo, N.A., Gosman, G.G., Nestler, J.E., Giudice, L.C., Leppert, P.C. and Myers, E.R., Cooperative Multicenter Reproductive Medicine Network (2007) Clomiphene, Metformin, or Both for Infertility in the Polycystic Ovary Syndrome. The New England Journal of Medicine, 356, 551-566. http://dx.doi.org/10.1056/NEJMoa063971

[23] Ehrmann, D.A. (2005) Polycystic Ovary Syndrome. The New England Journal of Medicine, 352, 1223-1236. http://dx.doi.org/10.1056/NEJMra041536

[24] San Millán, J.L., Botella-Carretero, J.I., Álvarez-Blasco, F., Luque-Ramírez, M., Sancho, J., Moghetti, P., et al. (2005) A Study of the Hexose-6-Phosphate Dehydrogenase Gene R453Q and 11 $\beta$-Hydroxysteroid Dehydrogenase Type 1 Gene 83557insA Polymorphism in the Polycystic Ovary Syndrome. The Journal of Clinical Endocrinology \& Metabolism, 90, 4157-4162. http://dx.doi.org/10.1210/jc.2004-1523

[25] Yildiz, B.O. (2006) Diagnosis of Hyperandrogenism: Clinical Criteria. Best Practice \& Research Clinical Endocrinology \& Metabolism, 20, 167-176. http://dx.doi.org/10.1016/j.beem.2006.02.004

[26] Martin, K.A., Chang, R.J., Ehrmann, D.A., Ibanez, L., Lobo, R.A., Rosenfield, R.L., et al. (2008) Evaluation and Treatment of Hirsutism in Premenopausal Women: An Endocrine Society Clinical Practice Guideline. The Journal of Clinical Endocrinology \& Metabolism, 93, 1105-1120. http://dx.doi.org/10.1210/jc.2007-2437

[27] Archer, J.S. and Chang, R.J. (2004) Hirsutism and Acne in Polycystic Ovary Syndrome. Best Practice \& Research Clinical Obstetrics \& Gynaecology, 18, 737-754. http://dx.doi.org/10.1016/j.bpobgyn.2004.05.007

[28] Fraser, I.S. and Kovacs, G. (2004) Current Recommendations for the Diagnostic Evaluation and Follow-Up of Patients Presenting with Symptomatic Polycystic Ovary Syndrome. Best Practice \& Research Clinical Obstetrics \& Gynaecology, 18, 813-823. http://dx.doi.org/10.1016/S1521-6934(04)00106-3

[29] Ozdemir, S., Ozdemir, M., Gorkemli, H., Kiyici, A. and Bodur, S. (2010) Specific Dermatologic Features of the Polycystic Ovary Syndrome and Its Association with Biochemical Markers of the Metabolic Syndrome and Hyperandrogenism. Acta Obstetricia et Gynecologica Scandinavica, 89, 199-204. http://dx.doi.org/10.3109/00016340903353284

[30] Rogers, N.E. and Avram, M.R. (2008) Medical Treatments for Male and Female Pattern Hair Loss. Journal of the American Academy of Dermatology, 59, 547-566. http://dx.doi.org/10.1016/j.jaad.2008.07.001

[31] Lee, A.T. and Zane, L.T. (2007) Dermatologic Manifestations of Polycystic Ovary Syndrome. American Journal of Clinical Dermatology, 8, 201-219. http://dx.doi.org/10.2165/00128071-200708040-00003

[32] Araujo, L.M., Porto, M.V., Netto, E.M. and Ursich, M.J. (2002) Association of Acanthosis Nigricans with Race and Metabolic Disturbances in Obese Women. Brazilian Journal of Medical and Biological Research, 35, 59-64. http://dx.doi.org/10.1590/S0100-879X2002000100008

[33] Izzo, C.R. (2013) Infertilidade de causa hormonal para o ginecologista. Boletim da SBRH: Artigos Científicos, Ano 6, Número 2. http://www.sbrh.org.br/Acesso

[34] Piazza, V. (2009) Sindrome dll’ovaio policistico. Disponívelem: http://www.vincenzopiazza.it/sindrome_ovaio_policistico.asp

[35] ACOG Committee on Practice Bulletins-Gynecology (2009) ACOG Practice Bulletin No. 108: Polycystic Ovary Syndrome. Obstetrics \& Gynecology, 114, 936-949.

[36] Saúde Reprodutiva Infertilidade (2008) Direcção-Geral da Saúde Programa Nacional de Saúde Reprodutiva Saúde reprodutiva/Infertilidade/Direcção-Geral da Saúde Lisboa: DGS. 16 p.

[37] Martins, M.A., Carrilho, F.J., Alves, V.A.F., Castilho, E.A., Cerri, G.G. and Wen, C.L. (2009) Clínica Médica, 1, 501-506.

[38] Legro, R.S., Arslanian, S.A., Ehrmann, D.A., Hoeger, K.M., Murad, M.H., Pasquali, R. and Welt, C.K. (2013) Diagnosis and Treatment of Polycystic Ovary Syndrome: An Endocrine Society Clinical Practice Guideline. The Journal of Clinical Endocrinology \& Metabolism, 98, 4565-4592. http://dx.doi.org/10.1210/jc.2013-2350 
[39] Norman, R.J., Wu, R. and Stankiewicz, M.T. (2004) Polycystic Ovary Syndrome. The Medical Journal of Australia, 180, $132-137$.

[40] Homburg, R. (2008) Polycystic Ovary Syndrome. Best Practice \& Research Clinical Obstetrics \& Gynaecology, 22, 261-274. http://dx.doi.org/10.1016/j.bpobgyn.2007.07.009

[41] Kaaks, R., Lukanova, A. and Kurzer, M.S. (2002) Obesity, Endogenous Hormones, and Endometrial Cancer Risk: A Synthetic Review. Cancer Epidemiology, Biomarkers \& Prevention, 11, 1531-1543.

[42] Sun, X., Zhang, D. and Zhang, W. (2013) Effect of Metformin on Ovulation and Reproductive Outcomes in Women with Polycystic Ovary Syndrome: A Meta-Analysis of Randomized Controlled Trials. Archives of Gynecology and Obstetrics, 288, 423-430. http://dx.doi.org/10.1007/s00404-013-2756-5

[43] Li, Y., Li, Y., Yu Ng, E.H., Stener-Victorin, E., Hou, L., Wu, T., Han, F., et al. (2011) Polycystic Ovary Syndrome Is Associated with Negatively Variable Impacts on Domains of Health-Related Quality of Life: Evidence from a Meta-Analysis. Fertility and Sterility, 96, 452-458. http://dx.doi.org/10.1016/j.fertnstert.2011.05.072 